Article

\title{
Facile Synthesis and Self-Assembly of Amphiphilic Polyether-Octafunctionalized Polyhedral Oligomeric Silsesquioxane via Thiol-Ene Click Reaction
}

\author{
Yong Xia ${ }^{1, *} \mathbb{D}$, Sha Ding ${ }^{1}$, Yuejun Liu ${ }^{1}$ and Zhengjian $\mathrm{Qi}^{2}$ \\ 1 Key Laboratory of Advanced Packaging Materials and Technology of Hunan Province, \\ Hunan University of Technology, Zhuzhou 412007, China; 421298314@163.com (S.D.); \\ yjliu_2005@126.com (Y.L.) \\ 2 College of Chemistry and Chemical Engineering, Southeast University, Nanjing 211189, China; \\ qizhengjian506@163.com \\ * Correspondence: xiayong@hut.edu.cn; Tel.: +86-0731-2218-2088
}

Academic Editors: Katja Loos and Alexander Böker

Received: 17 May 2017; Accepted: 26 June 2017; Published: 28 June 2017

\begin{abstract}
We demonstrated here a facile and efficient synthesis of polyhedral oligomeric silsesquioxane-based amphiphilic polymer by thiol-ene click chemistry. The properties of polyhedral oligomeric silsesquioxane (POSS)-PEG amphiphilic polymers were studied in detail by a combination of ${ }^{1} \mathrm{H}$ NMR, ${ }^{13} \mathrm{C}$ NMR, ${ }^{29} \mathrm{Si}$ NMR FT-IR, GPC, and TG analysis. The newly-designed thiol-ene protocol obtains only anti-Markovnikov addition POSS-based amphiphilic polymers when compared with platinum-catalysed hydrosilylation method. The critical micelle concentration (CMC) of the resulting polymers are in the range of 0.011 to $0.050 \mathrm{mg} / \mathrm{mL}$, and dynamic light scattering (DLS) results revealed that the obtained amphiphilic polymers can self-assemble into nanoparticles in aqueous solutions with a bimodal (two peaks) distribution. Furthermore, the specific polymer showed obvious thermo-sensitive behaviour at $45.5^{\circ} \mathrm{C}$.
\end{abstract}

Keywords: amphiphilic; thiol-ene chick chemistry; CMC; thermo-sensitive

\section{Introduction}

In recent years, organic/inorganic hybrid nanomaterials have aroused widespread interest. Since they are combined with the traditional organic polymers' easy workability, toughness, and thermal stability and oxidation resistance properties of inorganic compounds, this kind of materials play a key role in the development of high performance and high functional materials [1-4]. At present, there are many different types of nanocomposites, such as three-dimensional sol-gel materials [5-9], ceramic polymer [10-12], organic/inorganic polymer blend [13-15], and polyhedral oligomeric silsesquioxane (POSS) nanocomposites [16-21]. POSS-based polymer is a kind of nanoscale silicate functional material with cage-like segments directly bound to the polymer chains. Such newly-developed nanocomposite materials show synergistic properties of organic/inorganic materials, and present some new characteristics [22,23].

POSS has a nanoscale silicon core and eight organic functional groups on the surface, with sizes from 0.7 to $1.5 \mathrm{~nm}$. The three-dimensional nanostructures of POSS can be used to build all types of hybrid materials with specific performance and controllable nanostructures [24]. Attracted by the fascinating vistas, POSS has potential applications in high-performance materials and biomedical fields [25-28], but its low water-solubility is the main impediment for real-world applications. Grafting hydrophilic groups on POSS is one of the effective methods to achieve water-soluble materials [29,30]. As is known to all, polyethylene glycol (PEO) is a water-soluble polymer with excellent properties, such 
as non-toxicity, lubricity, and biocompatibility. PEO is widely applied in biotechnology, in addition, it is a type of very important solid polymer electrolyte in lithium ion batteries because of its ability of dissolve the lithium ion [31]. Kim et al. [32] reported the synthesis and characterization of amphiphilic telechelics incorporating polyhedral oligosilsesquioxane (POSS-PEG). They obtained amphiphilic telechelic polymers with different POSS content by changing the PEG molecular weight, and studied the effect of POSS content on the crystallization behaviour of PEG. The results showed that different morphology and thermodynamic properties of the amphiphilic telechelic polymers could be obtained through controlling the ratio of hydrophilic PEG homopolymer and hydrophobic POSS macromolecular monomer. Subsequently, Kim et al. [33,34] systematically studied the polymer morphology, microstructure and rheological properties of POSS-PEG, and the impacts of structure and solvent polarity on bonding behavior in dilute solution using dilute solution viscosity method. Maitra et al. [35] synthesized a series of ethylene oxide oligomers functional silsesquioxane, reveals how the POSS silicon surface affect thermal behavior of ethylene oxide oligomers, $T_{\mathrm{g}}$ increases with the increase of the length of ethylene oxide chain, and inhibiting crystallization.

Although there have been many reports about the synthesis and application of polyethylene oxide functionalized silsesquioxane [36-43], but the preparation methods generally involve the Pt-catalyzed hydrosilylation between the terminal Si-H groups on the POSS cube with an unsaturated carbon double bond. The traditional method possesses some disadvantages: this method requires noble metal platinum, which is very expensive. It is difficult to get rid of the residues in purification process, which not only affects the product performance, but also limits its application in the field of biological medicine. This reaction generally requires strict water-free and oxygen-free conditions. The hydrosilylation reaction usually results in a mixture of Markovnikov and anti-Markovnikov addition products [44], which might complicate the structure-activity relationship of the amphiphilic copolymer. In addition, it is very difficult to obtain the high hydrophilic eight substitution product due to the limit of reaction efficiency and the influence of steric hindrance. Li et al. [45] successfully synthesize the eight functional POSS-PEG polymer using the copper-catalyzed alkyne-azide cycloaddition, which has faster reaction rate and higher yield. Nevertheless, the residues of heavy metal copper catalyst still have a certain influence on its application in the biomedical field. Therefore, a series of eight polyethylene oxide functionalized POSS amphiphilic polymers are synthesized through the metal-free thiol-ene click reaction, theirs self-assembly behaviour in aqueous solution, thermal stability, and thermo-responsive are systematically studied.

\section{Experimental Section}

\subsection{Materials}

Allyl-terminated polyether A $(1000 \mathrm{~g} / \mathrm{mol}, \mathrm{EO} / \mathrm{PO}=70 / 30), \mathbf{B}(1200 \mathrm{~g} / \mathrm{mol}, \mathrm{EO} / \mathrm{PO}=85 / 15)$, and $\mathrm{C}(2000 \mathrm{~g} / \mathrm{mol}, \mathrm{EO} / \mathrm{PO}=40 / 60)$ were provided by Jiangsu Maysta Chemical Co. Ltd. (Nanjing, China) 2,2-dimethoxy-2-phenylacetophenone (DMPA) was purchased from Aladdin (Shanghai, China) and used as received. Mercaptopropyltrimethoxysilane (MPT) and tetramethylammonium hydroxide $\left(\left(\mathrm{CH}_{3}\right)_{4} \mathrm{NOH}\right)$ were purchased from J and $\mathrm{K}$ Chemical (Shanghai, China) and used without any further purification. Tetrahydrofuran (THF), diethyl ether, acetone, and concentrated hydrochloric acid were of analytical grade. In this work, the thiol-ene reaction was carried out under ambient conditions, the other reactions were carried out under a dry nitrogen atmosphere. The photo-induced reactions was carried out by a UV lamp $\left(20 \mathrm{~mW} \cdot \mathrm{cm}^{-2}, \lambda=365 \mathrm{~nm}\right.$; LP-40A; LUYOR Corporation, Shanghai, China).

\subsection{Synthesis of Octamercaptopropyl-POSS (POSS-SH)}

POSS-SH is prepared according to our previous work [46]. The resulting viscous solution was dissolved in $\mathrm{CH}_{2} \mathrm{Cl}_{2}$ and then washed three times with $\mathrm{H}_{2} \mathrm{O}$. The $\mathrm{CH}_{2} \mathrm{Cl}_{2}$ phase was dried with anhydrous $\mathrm{Na}_{2} \mathrm{SO}_{4}$ and concentrated to obtain POSS-SH in 76\% yield. IR (KBr; $\left.v, \mathrm{~cm}^{-1}\right): 2929(\mathrm{~m})$, 2555 (w), 2849 (m), 1401 (m), 1122 (vs), 1032 (s), 562 (m), 472 (m). ${ }^{1} \mathrm{H}$ NMR (300 MHz, CDCl ${ }_{3}$; , 
ppm): 0.76 (double, $\left.\mathrm{Si}-\mathrm{CH}_{2}-\right), 1.71\left(\mathrm{~s},-\mathrm{CH}_{2}-\right), 2.56\left(\mathrm{~s},-\mathrm{CH}_{2}-\mathrm{S}\right), 1.37(\mathrm{br},-\mathrm{SH}) .{ }^{13} \mathrm{C}$ NMR $(300 \mathrm{MHz}$, $\left.\mathrm{CDCl}_{3} ; \delta, \mathrm{ppm}\right): 13.46\left(\mathrm{Si}-\mathrm{CH}_{2}-\right), 29.87\left(\mathrm{Si}-\mathrm{CH}_{2}-\mathrm{CH}_{2}-\right), 30.16\left(-\mathrm{CH}_{2}-\mathrm{SH}\right) .{ }^{29} \mathrm{Si} \mathrm{NMR}\left(400 \mathrm{MHz}, \mathrm{CDCl}_{3}\right.$; $\delta, \mathrm{ppm}):-67.20$. GPC-result, $M_{\mathrm{n}}: 1005 \mathrm{~g} / \mathrm{mol}$, PDI: 1.02 .

\subsection{Synthesis of Polyether-Octafunctionalized POSS (POSS-PEG)}

For the purpose of discussions, the POSS-PEG amphiphilic polymers containing different allyl-terminated polyethers are defined as $\mathbf{P}_{\mathbf{1}}, \mathbf{P}_{\mathbf{2}}$, and $\mathbf{P}_{\mathbf{3}}$, respectively. The synthetic route of POSS-PEG amphiphilic polymer is shown in Scheme 1 . The $\mathbf{P}_{\mathbf{1}}$ was synthesized by thiol-ene click chemistry as follows: $0.5 \mathrm{~g}$ octamercaptopropyl-POSS (POSS-SH), $4.4 \mathrm{~g}$ allyl-terminated polyether $\mathbf{A}$ and $0.08 \mathrm{~g}$ DMPA were dissolved by $8 \mathrm{~mL}$ dry THF solvent. The system was stirred gently for 30 min under UV light irradiation, then placed in a dialysis bag (cutoff $M_{\mathrm{n}}: 3.5 \mathrm{kDa}$ ) and dialyzed against water for three days to get rid of residual polyether, replacing dialysate every $4 \mathrm{~h}$ and, finally, obtaining the target product by drying the inside mixture. Yield: $98 \%,{ }^{1} \mathrm{H}$ NMR $\left(300 \mathrm{MHz}, \mathrm{CDCl}_{3}, \mathrm{ppm}\right): \delta=0.71$ $\left(\mathrm{m}, \mathrm{SiCH}_{2}-\right), 1.08-1.13\left(\mathrm{~d},-\mathrm{CH}_{3}\right), 1.64\left(\mathrm{t},-\mathrm{SiCH}_{2} \mathrm{CH}_{2}-\right), 1.81\left(\mathrm{~m},-\mathrm{SCH}_{2} \mathrm{CH}_{2}-\right), 2.51\left(\mathrm{t},-\mathrm{CH}_{2} \mathrm{SCH}_{2}-\right)$, 3.27-3.85 (m, $\left.-\mathrm{OCH}_{2} \mathrm{CH}_{2} \mathrm{O}-,-\mathrm{OCH}_{2} \mathrm{CH}\left(\mathrm{CH}_{3}\right) \mathrm{O}-\right)$. GPC-result, $M_{\mathrm{n}}: 13510 \mathrm{~g} / \mathrm{mol}$, PDI: 1.15 .

The synthetic methods of $\mathbf{P}_{\mathbf{2}}$ (polyether: $M_{\mathrm{n}}=1200 \mathrm{~g} / \mathrm{mol}, \mathrm{EO} / \mathrm{PO}=85 / 15$ ) and $\mathbf{P}_{\mathbf{3}}$ (polyether: $\left.M_{\mathrm{n}}=2000 \mathrm{~g} / \mathrm{mol}, \mathrm{EO} / \mathrm{PO}=40 / 60\right)$ are identical to $\mathbf{P}_{\mathbf{1}}$.

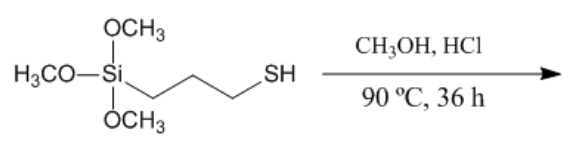

$$
\begin{aligned}
& \mathrm{R}_{\mathrm{R}} \\
& \mathrm{R}=\mathrm{C}_{3} \mathrm{H}_{6} \mathrm{SH}(\mathrm{POSS}-\mathrm{SH})
\end{aligned}
$$

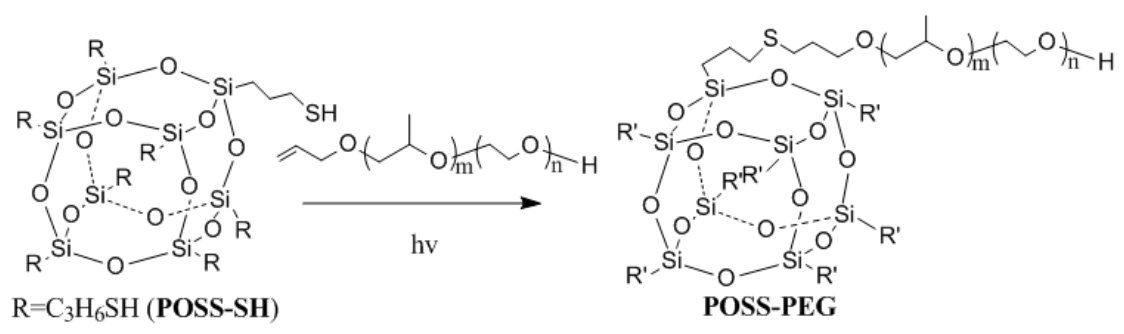

Scheme 1. The synthesis of POSS-PEG polymer.

\subsection{Characterizations}

FT-IR was carried out using a Bruker TENSOR27 (Ettlingen, Germany) with the KBr pellet technique within the 4000 to $400 \mathrm{~cm}^{-1}$ region. ${ }^{1} \mathrm{H}$ NMR was carried out on a Bruker Avance (Billerica, MA, USA) 300 and $400 \mathrm{MHz}$ at $25{ }^{\circ} \mathrm{C}$. The solvent was deuterated chloroform $\left(\mathrm{CDCl}_{3}\right)$ without the interior label. The measurements of GPC were recorded on PL-GPC220 (Agilent, Palo alto, CA, USA) with THF as the eluent $(1.0 \mathrm{~mL} / \mathrm{min})$ at $40^{\circ} \mathrm{C}$. TG analysis was performed with a STARe System (Mettler Toledo, Columbus, $\mathrm{OH}$, USA). The heating rate was $20^{\circ} \mathrm{C} / \mathrm{min}$ under $\mathrm{N}_{2}$. TEM was recorded on a JEOL 2100 high-resolution TEM (JEOL Ltd., Tokyo, Japan) and Philips (CM 200, 80 kV, Amsterdam, The Netherlands).

\subsection{Critical Micelle Concentration (CMC) Measurements}

The CMC of the copolymers in ultrapure water was determined by fluorescence spectroscopy using pyrene as a hydrophobic fluorescent probe [47,48]. Briefly, a pyrene solution $\left(6.2 \times 10^{-6} \mathrm{M}\right.$ in acetone, $1 \mathrm{~mL}$ ) was placed in different vials, and the solvent was evaporated. Then, different concentrations of copolymer $(10 \mathrm{~mL})$ were added to those vials, respectively. Thus, the final concentration of pyrene was $6.2 \times 10^{-7} \mathrm{M}$ and the concentrations of polymer micelles were from 
$1.0 \times 10^{-4}$ to $1.0 \mathrm{~g} / \mathrm{L}$. Fluorescence measurements were carried out on a FluoroLog 3-TCSPC (Horiba Jobin Yvon Inc., Edison, NJ, USA) with a xenon light source (UXL-150S, Ushio, Japan). The slit widths of emission and excitation were $2 \mathrm{~nm}$. The excitation spectra were recorded from 290 to $360 \mathrm{~nm}$ with the emission $373 \mathrm{~nm}$. The emission spectra values $I_{338}$ and $I_{335}$, at 338 and $335 \mathrm{~nm}$, respectively, were used for subsequent calculations. The CMC was determined by plotting the $I_{338} / I_{335}$ ratio against the polymer concentration. The CMC was taken as the intersection of regression lines calculated from the linear portions of the plot.

\subsection{Dynamic Light Scattering (DLS)}

The DLS measurements were performed by a Brookhaven BI-200SM instrument (Holtsville, NY, USA) equipped with a $4 \mathrm{~mW}$ He-Ne laser $(\lambda=532 \mathrm{~nm})$ at an angle of $90^{\circ}$. The micelle copolymer solutions, with concentration $1 \mathrm{~g} / \mathrm{L}$, were prepared by direct dissolution of copolymers in ultrapure water. These samples, which were standing for $24 \mathrm{~h}$ before measurement, were filtered through $0.45 \mu \mathrm{m}$ PTFE microfilters. The results of the test were recorded using the intensity-weighted distribution of particle sizes.

\section{Results and Discussion}

\subsection{Characterization of Octamercaptopropyl-POSS (POSS-SH)}

The absorption bands of $\mathrm{Si-O}-\mathrm{Si}$ asymmetric stretching vibration are situated at 1109 and $1037 \mathrm{~cm}^{-1}$, showing in Figure S1. The large peak area may indicate that the obtained POSS-SH is composed primarily of Si-O-Si structure. The bands at 562 and $469 \mathrm{~cm}^{-1}$ are ascribed to the deformation vibration of POSS skeletal, and the stretching vibration of the bridge between caged silicon core and organic ligand $\mathrm{Si}-\mathrm{C}$ is located at $693 \mathrm{~cm}^{-1}$. The bands at 2930, 2819, and $1407 \mathrm{~cm}^{-1}$ are assigned to the stretching and bending vibrations of $-\mathrm{CH}$, while those at 1261 and $802 \mathrm{~cm}^{-1}$ are attributed to $\mathrm{C}-\mathrm{C}$ stretching vibration. It is even more exciting to clearly see the characteristic absorption of $-\mathrm{SH}$ stretching vibration, which is located at $2555 \mathrm{~cm}^{-1}$.

${ }^{1} \mathrm{H}$ NMR spectrum of POSS-SH (Figure S2) illustrates four strong resonance signals corresponding to different $\mathrm{H}$ atoms in its structure. The chemical shifts of these protons are assigned at $0.76 \mathrm{ppm}$ (double, $\left.\mathrm{SiCH}_{2}-\right), 1.71 \mathrm{ppm}\left(\mathrm{s},-\mathrm{CH}_{2}-\right), 2.56 \mathrm{ppm}\left(\mathrm{s},-\mathrm{CH}_{2} \mathrm{~S}\right)$, and $1.37 \mathrm{ppm}(\mathrm{br},-\mathrm{SH})$, which agree well with $\mathrm{a}, \mathrm{b}, \mathrm{c}$ and $\mathrm{d}$ groups on the side chains of the POSS-SH framework. ${ }^{13} \mathrm{C}$ NMR spectrum (Figure S3) shows that the chemical shift at $13.46 \mathrm{ppm}$ is assigned to the $-\mathrm{CH}_{2}$ group (carbon a) directly bound to the $\mathrm{Si}$ atom, while the others at 29.87 and $30.16 \mathrm{ppm}$ are attributed to carbon $\mathrm{b}$ and $\mathrm{c}$ of the mercaptopropyl group, respectively. On the other hand, the ${ }^{29} \mathrm{Si}$ NMR spectrum (Figure S3) reveals a sharp peak with a chemical shift at $67.20 \mathrm{ppm}$, ascribing to the Si atom of the POSS-SH. The results suggest that the cage-like Si-O-Si structure is well formed by the hydrolytic condensation of MTP and mercaptopropyl groups are symmetrically distributed on the cage-like POSS skeletal.

\subsection{Characterization of Amphiphilic Polymers}

Amphiphilic POSS-PEG polymers were synthesized by thiol-ene click chemistry with polyhedral oligomeric silsesquioxane and allylic polyether as starting materials.

In ${ }^{1} \mathrm{H}$ NMR (Figure 1) of $\mathbf{P}_{\mathbf{1}}$, all of the proton signal belonging to the polyether fragment and the POSS-SH fragment can be observed. The disappearance of S-H signal at $1.37 \mathrm{ppm}$ and vinyl proton signal at 5.11 to $5.88 \mathrm{ppm}$ confirmed the formation of $\mathbf{P}_{\mathbf{1}}$. As previously reported, the thiol-ene reaction ( $\mathrm{Si}-\mathrm{Vi}$ and $-\mathrm{SH}$ ) may give either of two possible products (Markovnikov and anti-Markovnikov) [49-51]. The anti-Markovnikov addition product is dominant. However, the result of ${ }^{1} \mathrm{H}$ NMR indicates that there seem to be only anti-Markovnikov addition product in the current system. The number of epoxy propane (PO) unit in each polyether molecule was calculated by ${ }^{1} \mathrm{H}$ NMR of allyl polyether, then the number of polyether chains grafted on POSS could be determined by the integral area ratio of methyl at $1.08-1.13 \mathrm{ppm}$ and methylene at $0.71 \mathrm{ppm}$. The calculated results indicate that nearly 
eight polyether chains were grafted on each POSS, achieving entirely replace. However, due to the steric effect of high molecular weight polyether, amphiphilic POSS-PEG polymers synthesized by the hydrosilation method were difficult to be fully substituted. For example, Mya et al. [52] prepared POSS-PEG polymers by the hydrosilation, in which each polymer had only six polyether chains grafted onto silsesquioxane. The ${ }^{1} \mathrm{H}$ NMR of $\mathbf{P}_{\mathbf{2}}$ and $\mathbf{P}_{\mathbf{3}}$ were similar to the result of $\mathbf{P}_{\mathbf{1}}$.

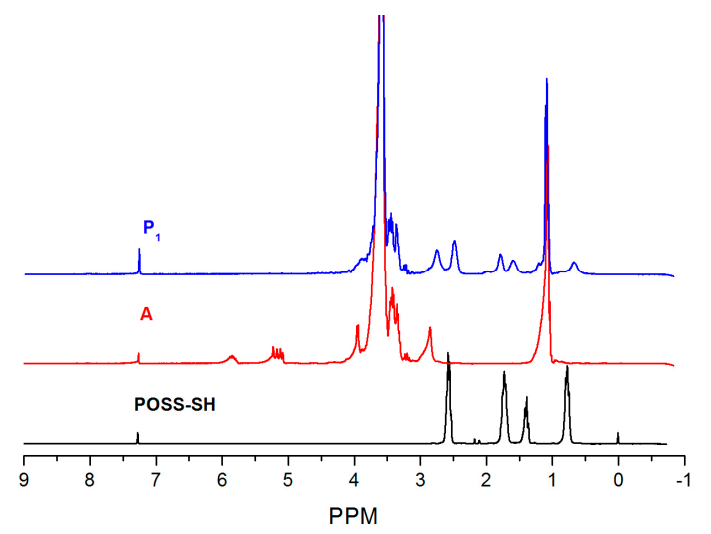

Figure 1. ${ }^{1} \mathrm{H}$ NMR spectra of $\mathbf{P}_{\mathbf{1}}$.

The IR spectrum of $\mathbf{P}_{\mathbf{1}}$ (Figure 2) clearly showed the symmetrical stretching vibration of $\mathrm{Si}-\mathrm{O}-\mathrm{Si}$ at $1111 \mathrm{~cm}^{-1}$, corresponding to the cage structure of silsesquioxane. The stretching vibration and bending vibration of Si-C were located at 1252 and $954 \mathrm{~cm}^{-1}$, respectively. Absorption bands at 954 and $843 \mathrm{~cm}^{-1}$ were characteristic peaks for $\mathrm{Si}-\mathrm{C}$ groups on its outside surface and the crystallization phases of polyether. Characteristic peaks of thiol at $2555 \mathrm{~cm}^{-1}$, and those peaks of olefin $\mathrm{C}-\mathrm{H}$ and $\mathrm{C}=\mathrm{C}$ disappeared, which suggested the completion of the click reaction.

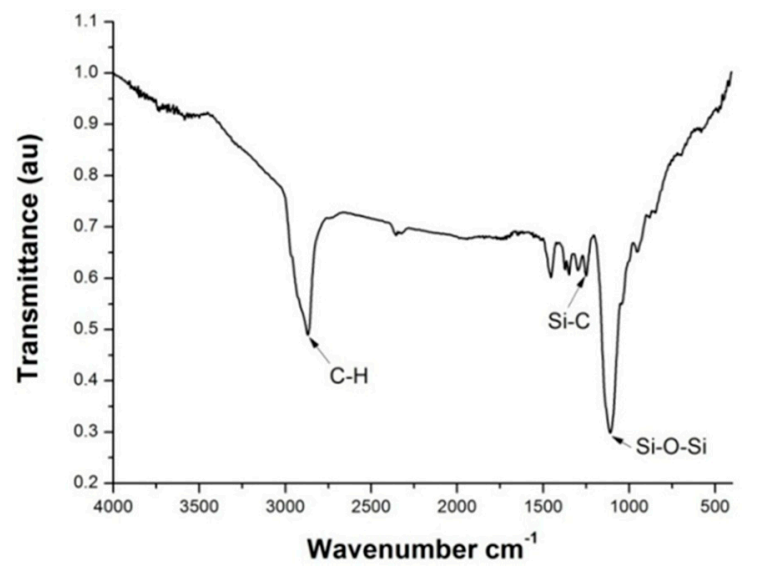

Figure 2. The FT-IR spectra of $\mathbf{P}_{\mathbf{1}}$.

Further verification of the successful synthesis was obtained from GPC analyses. Figure 3 shows representative GPC profiles of the Allyl-terminated polyether $\mathbf{A}, \mathbf{B}$, and $\mathbf{C}$ and the subsequent polymers $\left(\mathbf{P}_{1}, \mathbf{P}_{2}\right.$ and $\left.\mathbf{P}_{3}\right)$. A significant shift in the GPC traces (to a higher molecular weight) of the PEG and monomodal molecular weight distributions of the polymers indicates a successful click chemistry producing well-defined polymers. Furthermore, all of the three polymers have narrow molecular weight distribution, which are $1.15,1.23$, and 1.23 , respectively. The molecular weight of $\mathbf{P}_{\mathbf{1}}, \mathbf{P}_{\mathbf{2}}$, and $\mathbf{P}_{3}$, which increases with the increasing of the molecular weight of polyether, was $13,510,15,200$, and 20,800 $\mathrm{g} / \mathrm{mol}$, respectively. Obviously, the number-average molecular weight of polymers is greater than those of the sum of POSS molecule and eight polyether segments. However, the difference 
between the number-average molecular weight of the three polymers (1690 and $5600 \mathrm{~g} / \mathrm{mol}$ ) is very consistent with the result of the octa-substituted polymer.

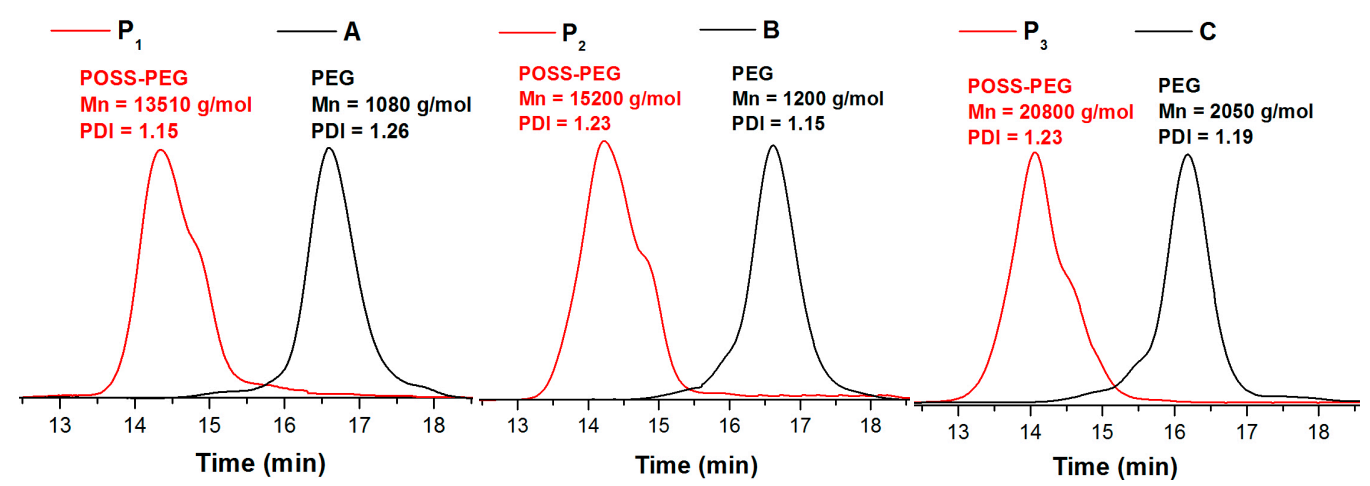

Figure 3. The GPC profiles of allyl-polyether and octa-substituted POSS polymers.

\subsection{Self-Assembly Behaviour of Polymers}

The micelle formation of the amphiphilic polymers was confirmed by fluorescence technique using pyrene as a probe. Figure 4 shows the fluorescence-excitation spectra of pyrene in POSS-PEG micelles at different concentrations. A red shift of the absorption peak from 335 to $338 \mathrm{~nm}$ was observed when the concentration of polymer was increased from $1.0 \times 10^{-4}$ to $2.0 \mathrm{mg} / \mathrm{mL}$. This red shift is attributed to the transfer of pyrene molecules from the hydrophilic environment to the hydrophobic micellar core. The results supply information on the location of the pyrene molecule in the system, that is, micelles are formed [53].

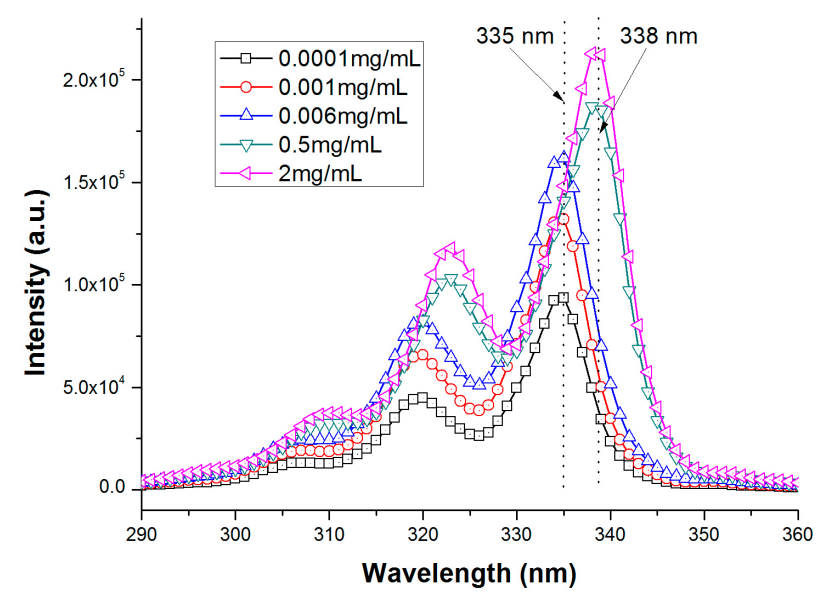

Figure 4. Excitation spectra of pyrene in aqueous solution of $\mathbf{P}_{\mathbf{1}}$ at various concentrations.

$\mathrm{CMC}$ is one of the key parameters for studying the formation of micelles and evaluating the stability of the resulting micelles. The intensity ratio of $I_{338} / I_{335}$ versus $\log C$ of the polymers in aqueous solution is shown in Figure 5. From these plots, the CMC of $\mathbf{P}_{\mathbf{1}}$ was determined to be approximately $1.1 \times 10^{-2} \mathrm{mg} / \mathrm{mL}$ through the intersection of two straight lines. The CMC of $\mathbf{P}_{\mathbf{2}}$ and $\mathbf{P}_{\mathbf{3}}$ were also obtained by the same method and shown in Figure S4. The CMC values of the three polymers increased as the proportion of polyether segment increased, which is consistent with the expected order (but it is different from polysiloxane system [54]). For polysiloxane system, because of the formation of vesicles and lamellae, the CMC values decreased as the proportion of polyether segment increased. Generally, amphiphilic polymers with higher content of the hydrophobic segments will cause stronger interactions between hydrophobic chains, leading to a more stable structure and, therefore, to a lower CMC value. 


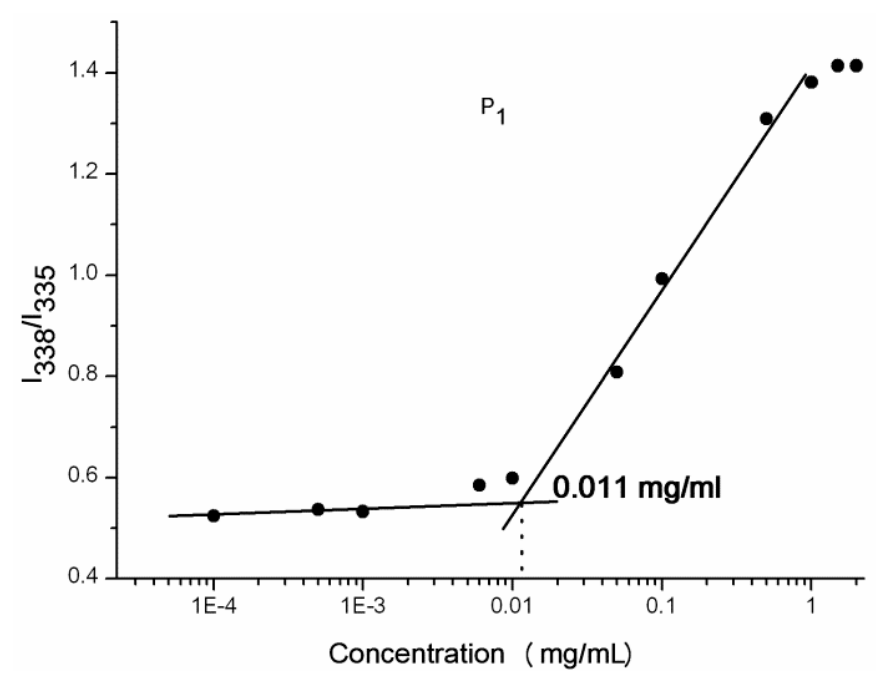

Figure 5. Variation of the intensity ratio $\left(I_{338} / I_{335}\right)$ as a function of $\mathbf{P}_{\mathbf{1}}$ concentrations, the dotted line shows the CMC value.

To study the self-assembly nanoparticle formation, the particle size was studied using dynamic light scattering, and the results are shown in Figure 6.

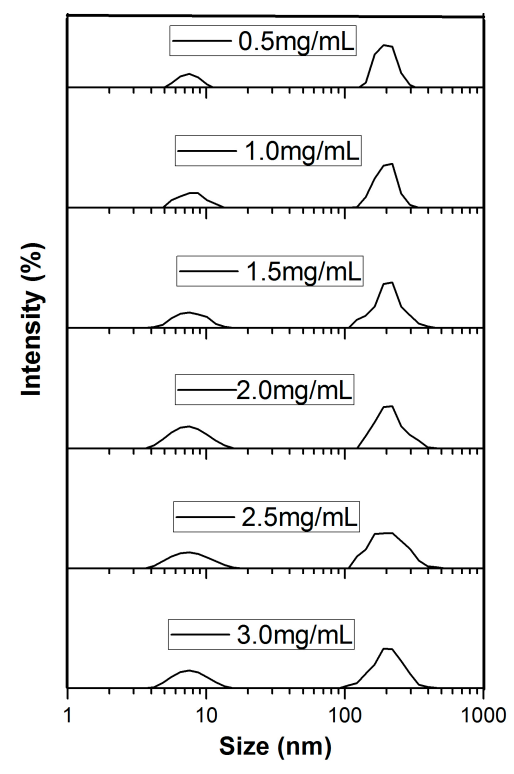

Figure 6. Size distribution of nanoparticles formed by different concentration of $\mathbf{P}_{\mathbf{1}}$ determined by DLS at $25^{\circ} \mathrm{C}$ in aqueous solutions.

The DLS results showed that a bimodal (two peaks) distribution was observed at all concentrations. The small peak represents the unassociated unimolecular micelle with $R_{\mathrm{h}}=\sim 7 \mathrm{~nm}$ and the dominant peaks attributed to the scattering from the large particles attributable to the aggregation of POSS-PEG. The unassociated unimolecular micelle and aggregate micelle are in a state of dynamic balance. The aggregation peak is observed, even at a concentration of $0.5 \mathrm{mg} / \mathrm{mL}$, suggesting that the CMC of POSS-PEG is lower than $0.5 \mathrm{mg} / \mathrm{mL}$, which is in agreement with the fluorescence measurements $(\mathrm{CMC}=0.011 \mathrm{mg} / \mathrm{mL})$. Figure 6 shows that both of the micelle sizes in aqueous solution do not depend on the polymer concentration, indicating that the measurements were carried out in the dilute concentration regime and that the micelle formation followed a closed association mechanism [55]. This is also consistent with the previous literature [56]. The particle size obtained from TEM 
micrographs are smaller than those obtained by DLS (Figure 7). TEM micrographs show the micelle with the corona shrinkage after the evaporation of water, while DLS gives the size of the swollen nanoparticles in aqueous solutions. From the TEM images, there are two kinds of size of micelles in the three polymers; the small micelles are several nanometers and the large micelles are dozens of nanometers. At the same time, there is a slight difference of the morphological micelles between the three polymers. These results are consistent with the measurements of DLS.
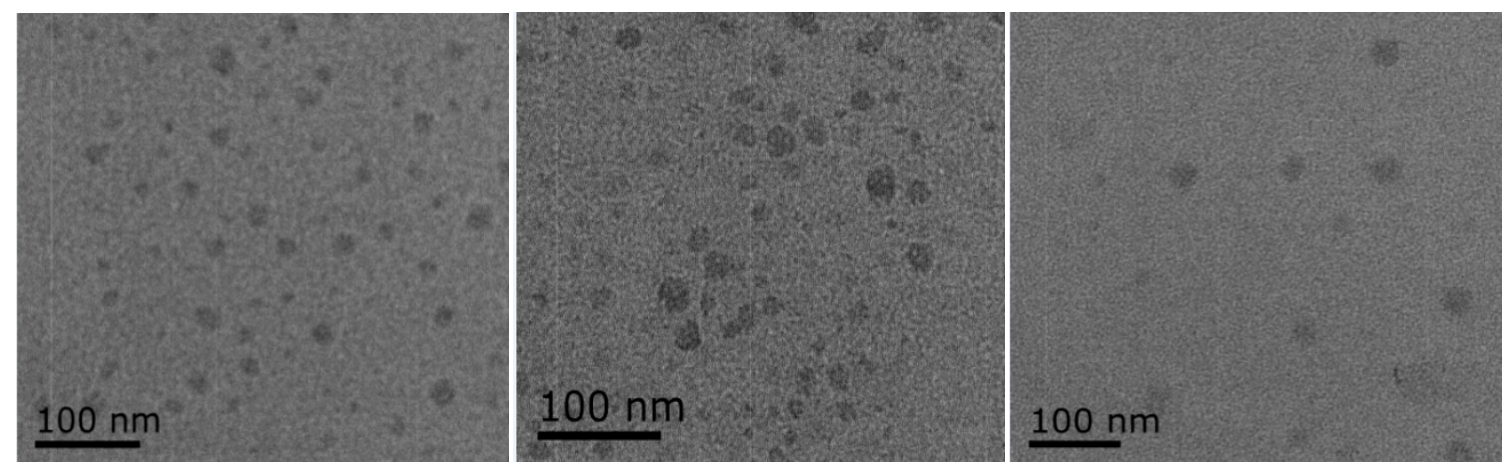

Figure 7. Typical TEM images of copolymers micelles $(1 \mathrm{mg} / \mathrm{mL})$, from left to right are $\mathbf{P}_{\mathbf{1}}, \mathbf{P}_{\mathbf{2}}$, and $\mathbf{P}_{3}$, respectively.

\subsection{Thermal Response Aggregation Behavior}

POSS-PEG polymer has the temperature sensitivity because of the hydrogen bonding interaction with the water molecules, and the hydrogen bond is destroyed gradually with the increase of temperature. In particular, the polyether backbone containing structural units of propylene glycol becomes hydrophobic with the increment of temperature. Micelles formed by the POSS-PEG polymer are comprised of hydrophobic POSS as the core and a hydrophilic polyether chain as the outer shell, which optimizes the surface contacting with water and prevent the micelles to aggregate further. If this hydrophilic outer shell becomes less hydrophilic with the increase of temperature, the micelles will aggregate, then resulting in turbidity of solution. Thus, the polymer has a lower critical solution temperature (LCST). The thermo-sensitive behaviors of POSS-PEG nanoparticles were investigated by measuring the cloud point $(\mathrm{CP})$. In order to ensure the formation of polymer nanoparticles, the concentrations of polymer aqueous solution were of $5 \mathrm{mg} / \mathrm{mL}$.

The polymers $\mathbf{P}_{\mathbf{1}}$ and $\mathbf{P}_{\mathbf{2}}$ did not show a significant temperature response behaviour, they were colourless and transparent, while the $\mathbf{P}_{3}$ changed from a colourless solution to turbid white (Figure 8). This is mainly because of the different composition of the polyether. In $\mathbf{P}_{\mathbf{1}}$ and $\mathbf{P}_{\mathbf{2}}$, the EO/PO of the polyether chain were $70 / 30$ and $85 / 15$, in which the PO content dominated thermo-sensitive behaviours $[57,58]$. While in the polymer $\mathbf{P}_{3}$, the EO/PO was $40 / 60$, thus $\mathbf{P}_{3}$ had obvious temperature sensitivity. The transmittance curve of the polymer $\mathbf{P}_{3}$ was shown in Figure 9 . When the temperature was above $\mathrm{CP}$, the transparent $\mathbf{P}_{\mathbf{3}}$ aqueous solution suddenly became turbid, caused by the aggregation of $\mathbf{P}_{3}$ nanoparticles. $\mathbf{P}_{3}$ aqueous solution was sensitive to temperature, and the range of the transition temperature was less than $2{ }^{\circ} \mathrm{C}$. It is worth noting that the thermo-sensitive behaviour of $\mathbf{P}_{3}$ nanoparticles was completely reversible. The transmittance of the $\mathbf{P}_{3}$ nanoparticles was about $100 \%$ at room temperature, and it was about 0 when heated to $60{ }^{\circ} \mathrm{C}$, and when cooled to room temperature, it was nearly $100 \%$ again. 


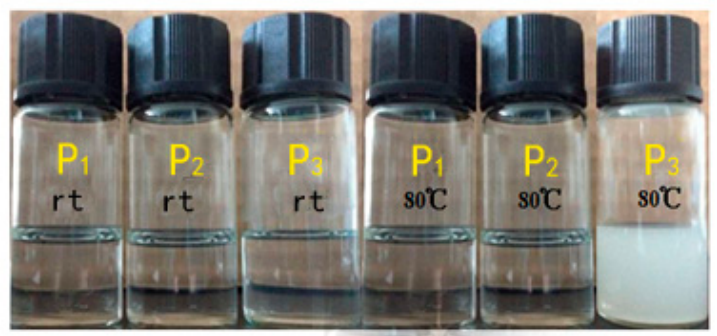

Figure 8. Digital photographs of transmittance variation of POSS-PEG aqueous solution $(5 \mathrm{mg} / \mathrm{mL})$.
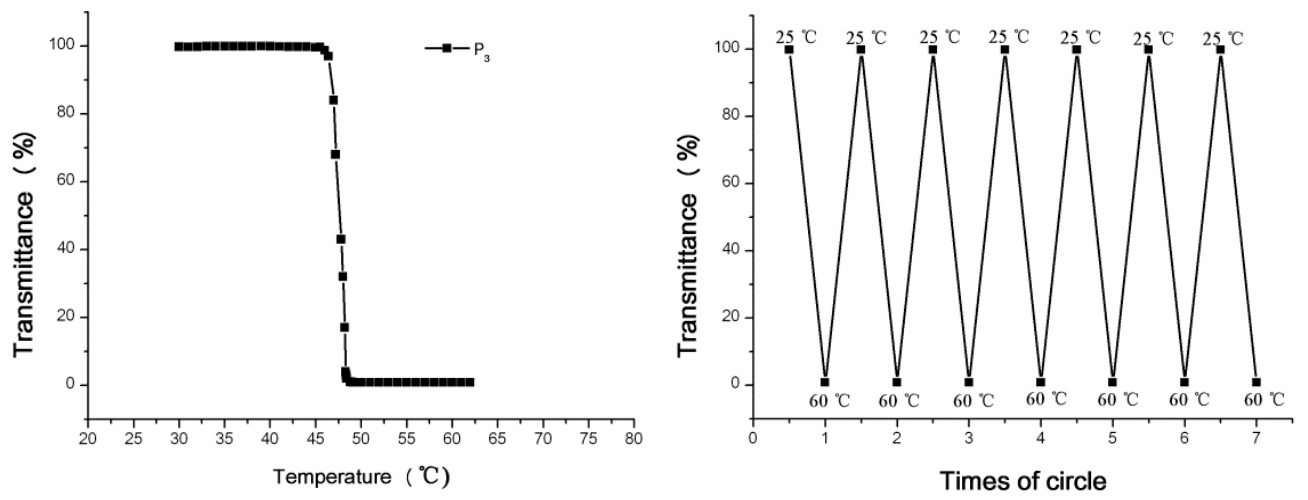

Figure 9. Temperature dependence of optical transmittance and reversible change of transmittance at $550 \mathrm{~nm}$ for $\mathbf{P}_{3}$ aqueous solution $(5 \mathrm{mg} / \mathrm{mL})$.

\subsection{Thermal Stability Analysis}

The thermodynamic behaviour of allyl-polyether and octa-substituted POSS in the nitrogen atmosphere was studied by TGA, and the results were shown in Figures S5 and S6, respectively. It could be found that the allyl-polyether was one step degradation, the initial decomposition temperature was from 270 to $310{ }^{\circ} \mathrm{C}$, and the decomposition temperature increased with the increase of the molecular weight of polyether. These results were consistent with that reported results about oligomeric allyl-polyether (molecular weight ranges from 146 to $322 \mathrm{~g} / \mathrm{mol}$ ) [37]. The results showed that the high molecular weight allyl-polyether had good thermodynamic stability.

The thermal decomposition temperature of the polymers were not much different from that of the corresponding polyether, which indicated the thioether bond formed by click reaction had no effect on the thermal stability of the polyether. The thermal analysis results of the small molecular weight polyether substituted POSS polymer showed that the thermal decomposition process was divided into two steps [37]. The first step was the polyether chain segment at $164-268{ }^{\circ} \mathrm{C}$, and the second step was the POSS cage to $\mathrm{SiO}_{2}$ in the range of $359-394{ }^{\circ} \mathrm{C}$. However, the current POSS-PEG polymers were different. Their curves of TGA had only one major degradation event similar to high molecular weight polyether, which might attribute to approximate decomposition temperature of high molecular weight polyether and the first decomposition temperature of POSS-SH (Figure 10). Although the second decomposition temperature of POSS-SH (decomposition temperature of POSS cage) presented about $400{ }^{\circ} \mathrm{C}$ (Figure S6), its decomposition process was not displayed in the TGA curves because the contents of POSS in polymers were very low. When the temperature was up to $600{ }^{\circ} \mathrm{C}$, the residual amounts of three allyl-polyethers were close to almost zero, while those of polymer $\mathbf{P}_{\mathbf{1}}, \mathbf{P}_{\mathbf{2}}$, and $\mathbf{P}_{\mathbf{3}}$ were $5.5 \%, 4.0 \%$, and $3.2 \%$, respectively. The results showed that the contents of POSS in polymers were $\mathbf{P}_{\mathbf{1}}>\mathbf{P}_{\mathbf{2}}>\mathbf{P}_{\mathbf{3}}$, which was consistent with the theoretical calculation results. 

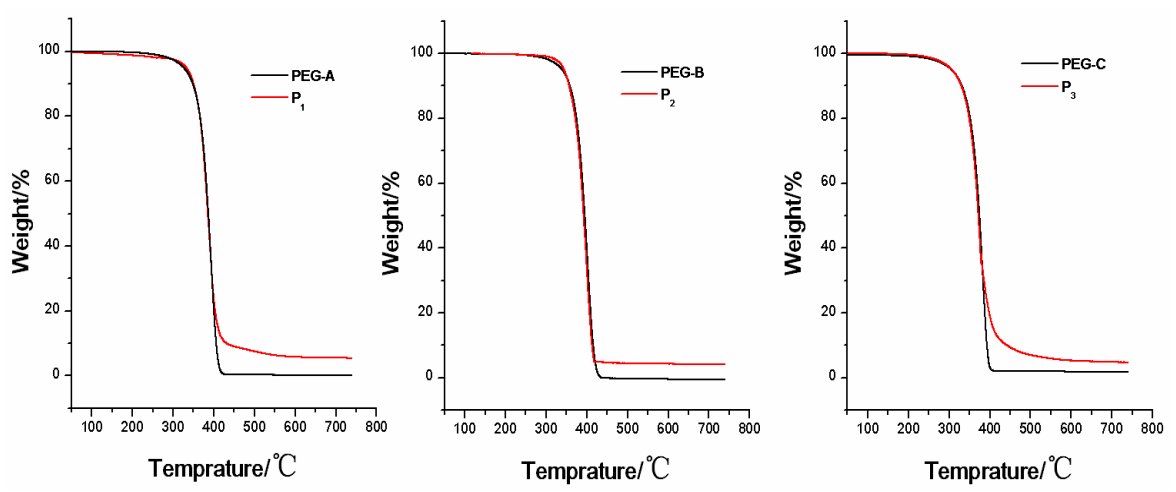

Figure 10. TGA curves of allyl-polyether and octa-substituted POSS (in $\mathrm{N}_{2}$ ).

\section{Conclusions}

Three octa-substituted POSS amphiphilic polymers $\left(\mathbf{P}_{\mathbf{1}}, \mathbf{P}_{\mathbf{2}}\right.$, and $\left.\mathbf{P}_{\mathbf{3}}\right)$ were successfully prepared via a newly-designed thiol-ene click chemistry protocol. The results of ${ }^{1} \mathrm{H} N M R,{ }^{13} \mathrm{C} N M R$, ${ }^{29} \mathrm{Si}$ NMR FT-IR, and gel permeation chromatography indicated the well-defined structures of the polymers. The experimental results showed that the amphiphilic polymers could form stable and bimodal nanoparticles directly by self-assembly in aqueous solution, and the formation of micelle followed closed association mechanism, in which the particle size was independent of the polymer concentration. Furthermore, the polymer $\mathbf{P}_{3}$ showed obvious temperature responsive behaviour. When the temperature rose to $45.5^{\circ} \mathrm{C}$, the solution quickly transformed into a turbid white solution and the range of the transition temperature was less than $2{ }^{\circ} \mathrm{C}$. Thermal analysis showed that the polymer had excellent thermal stability and the presence of the thioether bond did not affect its thermal stability. Due to the excellent properties of POSS, facile synthesis, amphipathy, direct self-assembly to form polymer nanoparticles, and thermo-sensitive behaviour, this kind of polymer would shine in many fields, especially in biomedical engineering.

Supplementary Materials: The following are available online at www.mdpi.com/2073-4360/9/7/251/s1, Figure S1: The infrared spectrum of POSS-SH, Figure S2: ${ }^{1} \mathrm{H}$ NMR spectra of POSS-SH, Figure S3: ${ }^{13} \mathrm{C}$ NMR spectra (a) and ${ }^{29}$ Si NMR spectra (b) of POSS-SH, Figure S4: Variation of the intensity ratio $\left(I_{338} / I_{335}\right)$ as a function of $\mathbf{P}_{\mathbf{2}}$ and $\mathbf{P}_{3}$ concentrations, the dotted line shows the CMC value, Figure S5: TGA curves of PEG-A, PEG-B, and PEG-C (in $\mathrm{N}_{2}$ ), Figure S6: TGA curve of POSS-SH (in $\mathrm{N}_{2}$ ).

Acknowledgments: The author wishes to acknowledge the financial supports from the National Natural Science Foundation of China (No. 11372108) and the Natural Science Foundation of Hunan Province (No. 14JJ5021).

Author Contributions: Yong Xia conceived and designed the experiments, and wrote articles, Sha Ding performed the experiments and analyzed the data, Yuejun Liu collected and analysed the data, and Zhengiian Qi supervised the project.

Conflicts of Interest: The authors declare no conflict of interest.

\section{References}

1. Sanchez, C.; Belleville, P.; Popall, M.; Nicole, L. Applications of advanced hybrid organic-inorganic nanomaterials: From laboratory to market. Chem. Soc. Rev. 2011, 40, 696-753. [CrossRef] [PubMed]

2. Descalzo, A.B.; Martinez-Manez, R.; Sancenon, R.; Hoffmann, K.; Rurack, K. The supramolecular chemistry of organic-inorganic hybrid materials. Angew. Chem. Int. Ed. 2006, 45, 5924-5948. [CrossRef] [PubMed]

3. Kaushik, A.; Kumar, R.; Arya, S.K.; Nair, M.; Malhotra, B.D.; Bhansali, S. Organic-inorganic hybrid nanocomposite-based gas sensors for environmental monitoring. Chem. Rev. 2015, 115, 4571-4606. [CrossRef] [PubMed]

4. Sharma, R.K.; Sharma, S.; Dutta, S.; Zboril, R.; Gawande, M.B. Silica-nanosphere-based organic-inorganic hybrid nanomaterials: Synthesis, functionalization and applications in catalysis. Green Chem. 2015, 17, 3207-3230. [CrossRef] 
5. Li, Z.; Chen, X.; Lin, C.; Zhao, N. The in vitro bioactive of sol-gel bioactive glass powders with three-dimensional lamellar structure. Adv. Powder Technol. 2012, 23, 13-15. [CrossRef]

6. Costa, D.O.; Dixon, S.J.; Rizkalla, A.S. One- and three-dimensional growth of hydroxyapatite nanowires during sol-gel-hydrothermal synthesis. ACS Appl. Mater. Interfaces 2012, 4, 1490-1499. [CrossRef] [PubMed]

7. Tiwari, J.N.; Tiwari, R.N.; Kim, K.S. Zero-dimensional, one-dimensional, two-dimensional and three-dimensional nanostructured materials for advanced electrochemical energy devices. Prog. Mater. Sci. 2012, 57, 724-803. [CrossRef]

8. Pan, A.; Wu, H.B.; Yu, L.; Zhu, T.; Lou, X.W. Synthesis of hierarchical three-dimensional vanadium oxide microstructures as high-capacity cathode materials for lithium-ion batteries. ACS Appl. Mater. Interfaces 2012, 4, 3874-3879. [CrossRef] [PubMed]

9. Kim, S.I.; Lee, J.S.; Ahn, H.J.; Song, H.K.; Jang, J.H. Facile route to an efficient nio supercapacitor with a three-dimensional nanonetwork morphology. ACS Appl. Mater. Interfaces 2013, 5, 1596-1603. [CrossRef] [PubMed]

10. Ionescu, E.; Kleebe, H.J.; Riedel, R. Silicon-containing polymer-derived ceramic nanocomposites (PDC-NCs): Preparative approaches and properties. Chem. Soc. Rev. 2012, 41, 5032-5052. [CrossRef] [PubMed]

11. Mera, G.; Gallei, M.; Bernard, S.; Ionescu, E. Ceramic nanocomposites from tailor-made preceramic polymers. Nanomaterials 2015, 5, 468-540. [CrossRef] [PubMed]

12. Bhandavat, R.; Kuhn, W.; Mansfield, E.; Lehman, J.; Singh, G. Synthesis of polymer-derived ceramic Si(B) $\mathrm{CN}$-carbon nanotube composite by microwave-induced interfacial polarization. ACS Appl. Mater. Interfaces 2011, 4, 11-16. [CrossRef] [PubMed]

13. Ren, S.; Chang, L.Y.; Lim, S.K.; Zhao, J.; Smith, M.; Zhao, N.; Bulovic, V.; Bawendi, M.; Gradecak, S. Inorganic-organic hybrid solar cell: Bridging quantum dots to conjugated polymer nanowires. Nano Lett. 2011, 11, 3998-4002. [CrossRef] [PubMed]

14. Chen, Y.Y.; Ford, W.T.; Materer, N.F.; Teeters, D. Facile conversion of colloidal crystals to ordered porous polymer nets. J. Am. Chem. Soc. 2000, 122, 10472-10473. [CrossRef]

15. Kim, J.; Kim, S.S.; Kim, K.H.; Jin, Y.H.; Hong, S.M.; San Hwang, S.; Cho, B.G.; Shin, D.Y.; Im, S.S. Applications of telechelic polymers as compatibilizers and stabilizers in polymer blends and inorganic/organic nanohybrids. Polymer 2004, 45, 3527-3533. [CrossRef]

16. Wang, F.K.; Lu, X.H.; He, C.B. Some recent developments of polyhedral oligomeric silsesquioxane (POSS)-based polymeric materials. J. Mater. Chem. 2011, 21, 2775-2782. [CrossRef]

17. Ghanbari, H.; Cousins, B.G.; Seifalian, A.M. A nanocage for nanomedicine: Polyhedral oligomeric silsesquioxane (POSS). Macromol. Rapid Commun. 2011, 32, 1032-1046. [CrossRef] [PubMed]

18. Ayandele, E.; Sarkar, B.; Alexandridis, P. Polyhedral oligomeric silsesquioxane (POSS)-containing polymer nanocomposites. Nanomaterials 2012, 2, 445-475. [CrossRef] [PubMed]

19. Lin, Y.; Jin, J.; Song, M.; Shaw, S.; Stone, C. Curing dynamics and network formation of cyanate ester resin/polyhedral oligomeric silsesquioxane nanocomposites. Polymer 2011, 52, 1716-1724. [CrossRef]

20. Geng, Z.; Huo, M.; Mu, J.; Zhang, S.; Lu, Y.; Luan, J.; Huo, P.; Du, Y.; Wang, G. Ultra low dielectric constant soluble polyhedral oligomeric silsesquioxane (POSS)-poly (aryl ether ketone) nanocomposites with excellent thermal and mechanical properties. J. Mater. Chem. C 2014, 2, 1094-1103. [CrossRef]

21. Li, Z.; Wu, D.; Liang, Y.; Fu, R.; Matyjaszewski, K. Synthesis of well-defined microporous carbons by molecular-scale templating with polyhedral oligomeric silsesquioxane moieties. J. Am. Chem. Soc. 2014, 136, 4805-4808. [CrossRef] [PubMed]

22. Fatieiev, Y.; Croissant, J.; Julfakyan, K.; Deng, L.; Anjum, D.H.; Gurinov, A.; Khashab, N. Enzymatically degradable hybrid organic-inorganic bridged silsesquioxane nanoparticles for in vitro imaging. Nanoscale 2015, 7, 15046-15050. [CrossRef] [PubMed]

23. Raftopoulos, K.N.; Pielichowski, K. Segmental dynamics in hybrid polymer/POSS nanomaterials. Prog. Polym. Sci. 2015, 7, 15046-15050. [CrossRef]

24. Wu, J.; Mather, P.T. Poss polymers: Physical properties and biomaterials applications. Polym. Rev. 2009, 49, 25-63. [CrossRef]

25. Croissant, J.G.; Cattoen, X.; Durand, J.O.; Man, M.W.C.; Khashab, N.M. Organosilica hybrid nanomaterials with a high organic content: Syntheses and applications of silsesquioxanes. Nanoscale 2016, 8, 19945-19972. [CrossRef] [PubMed] 
26. Au-Yeung, H.L.; Tam, A.Y.Y.; Leung, S.Y.L.; Yam, V.W.W. Supramolecular assembly of platinum-containing polyhedral oligomeric silsesquioxanes: An interplay of intermolecular interactions and a correlation between structural modifications and morphological transformations. Chem. Sci. 2017, 8, 2267-2276. [CrossRef] [PubMed]

27. Lee, J.H.; Lee, A.S.; Lee, J.C.; Hong, S.M.; Hwang, S.S.; Koo, C.M. Multifunctional mesoporous ionic gels and scaffolds derived from polyhedral oligomeric silsesquioxanes. ACS Appl. Mater. Interfaces 2017, 9, 3616-3623. [CrossRef] [PubMed]

28. Schafer, S.; Kickelbick, G. Simple and high yield access to octafunctional azido, amine and urea group bearing cubic spherosilicates. Dalton Trans. 2017, 46, 221-226. [CrossRef] [PubMed]

29. Gupta, J. Nanotechnology applications in medicine and dentistry. J. Investig. Clin. Dent. 2011, 2, 81-88. [CrossRef] [PubMed]

30. Chaloupka, K.; Malam, Y.; Seifalian, A.M. Nanosilver as a new generation of nanoproduct in biomedical applications. Trends Biotechnol. 2010, 28, 580-588. [CrossRef] [PubMed]

31. Ismail, I.; Noda, A.; Nishimoto, A.; Watanabe, M. Xps study of lithium surface after contact with lithium-salt doped polymer electrolytes. Electrochim. Acta 2001, 46, 1595-1603. [CrossRef]

32. Kim, B.S.; Mather, P.T. Amphiphilic telechelics incorporating polyhedral oligosilsesquioxane: 1 . Synthesis and characterization. Macromolecules 2002, 35, 8378-8384. [CrossRef]

33. Kim, B.S.; Mather, P.T. Morphology, microstructure, and rheology of amphiphilic telechelics incorporating polyhedral oligosilsesquioxane. Macromolecules 2006, 39, 9253-9260. [CrossRef]

34. Kim, B.S.; Mather, P.T. Amphiphilic telechelics with polyhedral oligosilsesquioxane (POSS) end-groups: Dilute solution viscometry. Polymer 2006, 47, 6202-6207. [CrossRef]

35. Maitra, P.; Wunder, S.L. Oligomeric poly(ethylene oxide)-functionalized silsesquioxanes: Interfacial effects on $T_{\mathrm{g}}, T_{\mathrm{m}}$, and $\Delta H_{\mathrm{m}}$. Chem. Mater. 2002, 14, 4494-4497. [CrossRef]

36. Lee, W.; Ni, S.L.; Deng, J.J.; Kim, B.S.; Satija, S.K.; Mather, P.T.; Esker, A.R. Telechelic poly(ethylene glycol)-POSS amphiphiles at the air/water interface. Macromolecules 2007, 40, 682-688. [CrossRef]

37. Markovic, E.; Ginic-Markovic, M.; Clarke, S.; Matisons, J.; Hussain, M.; Simon, G.P. Poly(ethylene glycol)-octafunctionalized polyhedral oligomeric silsesquioxane: Synthesis and thermal analysis. Macromolecules 2007, 40, 2694-2701. [CrossRef]

38. Markovic, E.; Matisons, J.; Hussain, M.; Simon, G.P. Poly(ethylene glycol) octafunctionalized polyhedral oligomeric silsesquioxane: Waxd and rheological studies. Macromolecules 2007, 40, 4530-4534. [CrossRef]

39. Miao, J.J.; Cui, L.; Lau, H.P.; Mather, P.T.; Zhu, L. Self-assembly and chain-folding in hybrid coil-coil-cube triblock oligomers of polyethylene- $b$-poly(ethylene oxide)- $b$-polyhedral oligomeric silsesquioxane. Macromolecules 2007, 40, 5460-5470. [CrossRef]

40. Mu, J.F.; Liu, Y.H.; Zheng, S.X. Inorganic-organic interpenetrating polymer networks involving polyhedral oligomeric silsesquioxane and poly(ethylene oxide). Polymer 2007, 48, 1176-1184. [CrossRef]

41. Li, Z.B.; Tan, B.H.; Jin, G.R.; Li, K.; He, C.B. Design of polyhedral oligomeric silsesquioxane (POSS) based thermo-responsive amphiphilic hybrid copolymers for thermally denatured protein protection applications. Polym. Chem. 2014, 5, 6740-6753. [CrossRef]

42. Wang, D.K.; Varanasi, S.; Strounina, E.; Hill, D.J.T.; Symons, A.L.; Whittaker, A.K.; Rasoul, F. Synthesis and characterization of a POSS-PEG macromonomer and POSS-PEG-PLA hydrogels for periodontal applications. Biomacromolecules 2014, 15, 666-679. [CrossRef] [PubMed]

43. Mohamed, M.G.; Jheng, Y.R.; Yeh, S.L.; Chen, T.; Kuo, S.W. Unusual emission of polystyrene-based alternating copolymers incorporating aminobutyl maleimide fluorophore-containing polyhedral oligomeric silsesquioxane nanoparticles. Polymers 2017, 9, 103. [CrossRef]

44. Mukbaniani, O.; Titvinidze, G.; Tatrishvili, T.; Mukbaniani, N.; Brostow, W.; Pietkiewicz, D. Formation of polymethylsiloxanes with alkyl side groups. J. Appl. Polym. Sci. 2007, 104, 1176-1183. [CrossRef]

45. Li, Y.J.; Wan, L.Q.; Huang, F.R.; Du, L. Core-shell octa(azidopropyl) POSS-PEO micelle via "click" chemistry. J. Mol. Liq. 2014, 196, 238-243. [CrossRef]

46. Xia, Y.; Yao, H.; Cui, M.; Ma, Y.; Kong, Z.; Wu, B.; Qi, Z.; Sun, Y. Theoretical and experimental investigations on mono-substituted and multi-substituted functional polyhedral oligomeric silsesquioxanes. RSC Adv. 2015, 5, 80339-80345. [CrossRef] 
47. Bakkour, Y.; Darcos, V.; Li, S.M.; Coudane, J. Diffusion ordered spectroscopy (DOSY) as a powerful tool for amphiphilic block copolymer characterization and for critical micelle concentration (CMC) determination. Polym. Chem. 2012, 3, 2006-2010. [CrossRef]

48. Pineiro, L.; Novo, M.; Al-Soufi, W. Fluorescence emission of pyrene in surfactant solutions. Adv. Colloid Interface Sci. 2015, 215, 1-12. [CrossRef] [PubMed]

49. Xue, L.; Wang, D.X.; Yang, Z.Z.; Liang, Y.; Zhang, J.; Feng, S.Y. Facile, versatile and efficient synthesis of functional polysiloxanes via thiol-ene chemistry. Eur. Polym. J. 2013, 49, 1050-1056. [CrossRef]

50. Shipp, D.A.; McQuinn, C.W.; Rutherglen, B.G.; McBath, R.A. Elastomeric and degradable polyanhydride network polymers by step-growth thiol-ene photopolymerization. Chem. Commun. 2009, 6415-6417. [CrossRef] [PubMed]

51. Rissing, C.; Son, D.Y. Thiol-ene reaction for the synthesis of multifunctional branched organosilanes. Organometallics 2008, 27, 5394-5397. [CrossRef]

52. Mya, K.Y.; Li, X.; Chen, L.; Ni, X.P.; Li, J.; He, C.B. Core-corona structure of cubic silsesquioxane-poly(ethylene oxide) in aqueous solution: Fluorescence, light scattering, and tem studies. J. Phys. Chem. B 2005, 109, 9455-9462. [CrossRef] [PubMed]

53. Kabanov, A.V.; Nazarova, I.R.; Astafieva, I.V.; Batrakova, E.V.; Alakhov, V.Y.; Yaroslavov, A.A.; Kabanov, V.A. Micelle formation and solubilization of fluorescent-probes in poly(oxyethylene-b-oxypropylene-b-oxyethylene) solutions. Macromolecules 1995, 28, 2303-2314. [CrossRef]

54. Xia, Y.; Yao, H.T.; Miao, Z.H.; Ma, Y.; Cui, M.F.; Yan, L.Q.; Ling, H.H.; Qi, Z.J. Facile synthesis and self-assembly of amphiphilic polydimethylsiloxane with poly(ethylene glycol) moieties via thiol-ene click reaction. RSC Adv. 2015, 5, 50955-50961. [CrossRef]

55. Chu, B. Laser Light Scattering: Basic Principles and Practice; Academic Press: New York, NY, USA, 1991.

56. Hussain, H.; Tan, B.H.; Seah, G.L.; Liu, Y.; He, C.B.; Davis, T.P. Micelle formation and gelation of (PEG-P(MA-POSS)) amphiphilic block copolymers via associative hydrophobic effects. Langmuir 2010, 26, 11763-11773. [CrossRef] [PubMed]

57. Louguet, S.; Rousseau, B.; Epherre, R.; Guidolin, N.; Goglio, G.; Mornet, S.; Duguet, E.; Lecommandoux, S.; Schatz, C. Thermoresponsive polymer brush-functionalized magnetic manganite nanoparticles for remotely triggered drug release. Polym. Chem. 2012, 3, 1408-1417. [CrossRef]

58. Persson, J.; Kaul, A.; Tjerneld, F. Polymer recycling in aqueous two-phase extractions using thermoseparating ethylene oxide-propylene oxide copolymers. J. Chromatogr. B 2000, 743, 115-126. [CrossRef] 